\title{
Improved the Durability of Thermal Barrier Coatings with Interface Modified
} by Three-Dimensional Mesh Patterns

\author{
L. Luo, ${ }^{\ddagger}$ X. Zhang, ${ }^{\S}$ Z. Zou, ${ }^{\ddagger}$ F. Guo, ${ }^{\ddagger}{ }^{\dagger}$ H. Qi,${ }^{\S}$ X. Zhao,,${ }^{\ddagger \dagger}$ and P. Xiao ${ }^{\natural}$ \\ ${ }^{\star}$ Shanghai Key Laboratory of Advanced High-temperature Materials and Precision Forming, Shanghai Jiao Tong University, \\ 800 Dongchuan Road, Shanghai 200240, China \\ ${ }^{\S}$ University of Michigan-Shanghai Jiao Tong University Joint Institute, Shanghai Jiao Tong University, Shanghai, China \\ "School of Materials, University of Manchester, Grosvenor Street, Manchester, UK
}

\begin{abstract}
An approach to improve the lifetime of air plasma sprayed (APS) thermal barrier coatings (TBCs) by modifying the interfacial microstructure has been reported. The laser powder deposition technique was employed to fabricate the mesh structure (with the same composition as the bond coat) at the ceramic-substrate interface. After thermal cycling test, the APS TBCs with the mesh exhibited a much less spallation degree $(5 \%-10 \%)$ compared with the reference samples without mesh $(>50 \%)$, implying that the mesh is effective in impeding the crack propagation along the interface. In addition, the effect of the mesh geometry parameters, e.g., height and spacing of mesh, on the spallation degree of TBCs was also investigated. Based on the results of experiment and calculation, the optimal mesh parameters were proposed.
\end{abstract}

Keywords: thermal barrier coatings; plasma spray; interfaces; microstructure

\section{Introduction}

$\mathrm{T}$ HERMAL barrier coatings (TBCs) are widely used in hot sections of aeroengines and industrial gas turbines to protect the superalloy components from aggressive environment. ${ }^{1,2}$ They usually comprise an yttria-stabilized zirconia (YSZ) layer deposited onto an intermetallic bond coat which is attached to a superalloy substrate. In the absence of mechanical damage, e.g., foreign object erosion, failure of the TBCs typically occurs in the vicinity of the thermally grown oxide (TGO), following a sequence of crack nucleation, propagation, and coalescence process. ${ }^{3,4}$ In general, failure of the TBCs is driven by stress $r$ in the YSZ top coat and the TGO (either from the thermal misfit stress or from the growth stress at high temperature), and resisted by the interfacial toughness between the coating and the substrate. ${ }^{5}$ In recent years, extensive efforts have been devoted to improving the durability of TBCs. For example, vertical cracks and porosity were deliberately introduced into top coat to improve the strain tolerance or reduce the driving force (i.e., stress) for TBCs spallation., 6 The reactive elements (e.g., Hf) were added into the bond coat to enhance the adhesion between the TGO and the bond coat, which primarily act as sulfur getter sites. ${ }^{8,9}$ However, few efforts have been made to optimize the interfacial microstructure to improve the lifetime of TBCs. Although conventional grit

T.Troczynski - contributing editor blasting procedure is usually beneficial to improving the coating adhesion by mechanical interlocking, the surface is relatively smooth ( $\mathrm{Ra}<20 \mu \mathrm{m})$ which is not capable to suppress the propagation of the interfacial cracks. ${ }^{10}$ If an obstacle is placed in the crack path to impede or deflect crack propagation, the fracture toughness should be improved. This could be a practical approach to fabricate long durability TBCs. Therefore, the objective of this work is to investigate if the lifetime of the TBCs could be improved by manipulating the interfacial microstructure.

\section{Experimental Procedure}

The substrate was a Hastelloy ${ }^{\circledR} \mathrm{X}$ alloy (Shanghai Niesheng Alloy Materials Co., Ltd., Shanghai, China ) with dimension $(50 \mathrm{~mm} \times 40 \mathrm{~mm} \times 5 \mathrm{~mm})$, which was cleaned with alcohol and grit blasted with 60 grit alumina prior to the deposition of the bond coat. Two types of mesh structure were designed. One was applied on the surface of the bond coat [Fig. 1(b)]. The other was directly applied on the substrate, followed by deposition of the bond coat [Fig. 1(c)]. The three-dimensional (3D) mesh structure at the ceramic-metal interface was fabricated by laser powder deposition (LPD) technique, which is schematically illustrated in Fig. 1(a). The LPD system comprises a multihopper powder feeder, a fiber laser, a coaxial nozzle, and control system. The LPD experiment was conducted with continuous-wave laser (YLS-2000: IPG Photonics, Pittsfield, MA). The laser spot is $500 \mu \mathrm{m}$ in diameter which was focused through a lens (200-mm focal length). The feedstock powder with nominal composition of Ni-24.7Cr5.11 Al-0.49Y wt \% was delivered by coaxial feeding nozzles with $10 \mathrm{~mm} / \mathrm{s}$ scan velocity and 3-4 g/min feed rate. Argon flow with a rate of $6 \mathrm{~L} / \mathrm{min}$ was used to prevent the oxidation of the powder during deposition.

Both the bond coat and the YSZ top coat were deposited using air plasma spraying technique (APS). The bond coat consists of NiCrAlY (Ni-24.7Cr-5.11Al-0.49Y in wt \%) with a thickness of $\sim 100 \mu \mathrm{m}$. The top coat is a standard $8 \mathrm{YSZ}$ with a thickness of $\sim 250 \mu \mathrm{m}$. For comparison, the TBCs samples without mesh were studied as a reference.

The specimens were cut into plates with a dimension of $10 \mathrm{~mm} \times 10 \mathrm{~mm} \times 5 \mathrm{~mm}$ before testing. Cyclic oxidation test was performed at $1150^{\circ} \mathrm{C}$ using a chamber furnace. Each cycle consists of a fast heat-up from room temperature to $1150^{\circ} \mathrm{C}$, a dwell of $10 \mathrm{~h}$, and air cooling after removing the specimens from the furnace. All samples were removed from furnace after 54 thermal cycles. To quantify the relative amount of spalled area, the surface images of the samples were recorded using optical microscope (BX-51M, Olympus, Tokyo, Japan) and processed using Image-J software, where the spalled and attached area were highlighted by white and black color, respectively. The spallation degree was defined
Manuscript No. 37635. Received October 13, 2015; approved May 24, 2016.

Authors to whom correspondence should be addressed. e-mails: xiaofengzhao@sjtu.edu.cn and fwguo2014@sjtu.edu.cn 


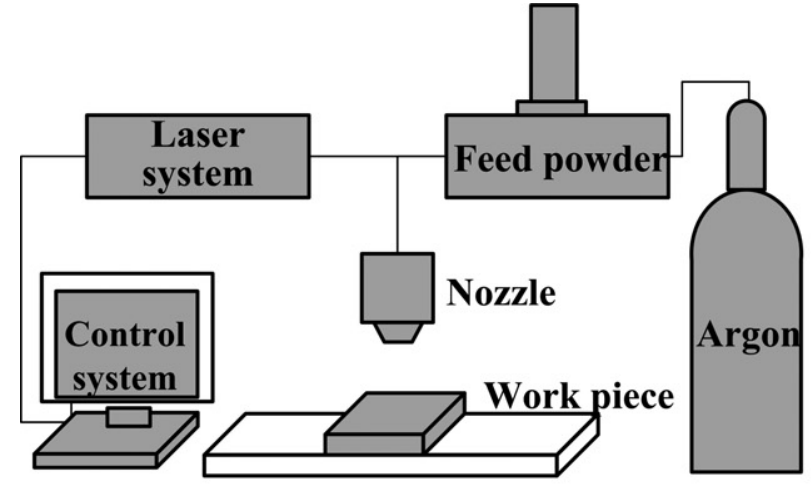

(a) (b)

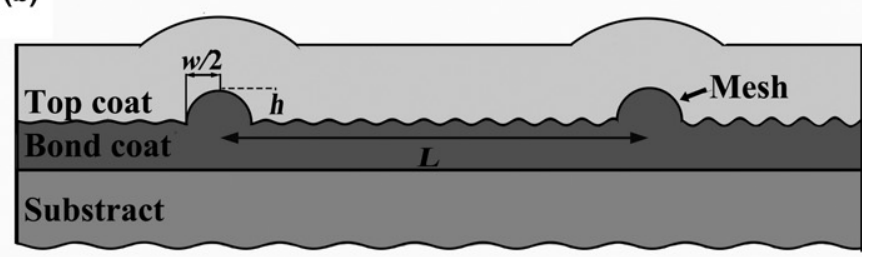

(c)

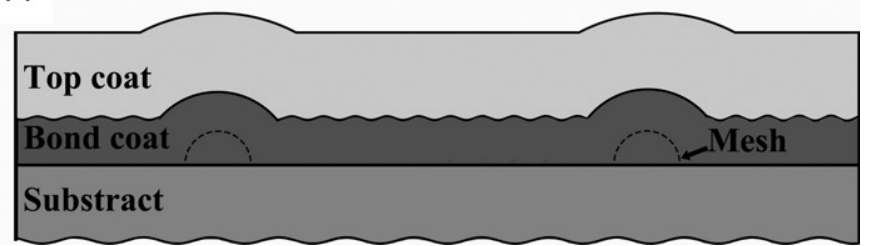

Fig. 1. (a) Schematic of the LPD system; (b) mesh on the surface of bond coat; (c) mesh on the surface of substrate.

as the ratio between the spallation area and the total area of the TBC. The specimens were embedded in epoxy, mechanically grounded and polished using diamond paste. The scanning electron microscopy (SEM, FEI Quanta 200, Eindhoven, Netherlands) in the backscattered electron mode was employed to examine the cross-sectional microstructure.

\section{Results and Discussion}

Figure 2 presents the textured surface and cross-sectional image of the as-deposited APS TBCs with the mesh structure. In this case, the mesh with spacing $(L)$ of $1.5,2.0$, and $2.5 \mathrm{~mm}$ was applied at the interface between the YSZ top coat and the bond coat [Fig. 2(b)]. Both the width $w$ and the height $h$ of the mesh are around $500 \mu \mathrm{m}$. The samples were exposed at $1150^{\circ} \mathrm{C}$ for lifetime test. After 54 thermal cycles, the spallation degree of the TBCs samples as a function of the mesh spacing was summarized and compared with the reference samples, shown in Fig. 2(c). The corresponding surface morphology was shown as inset. For the reference samples, i.e., the 8 YSZ TBCs without mesh, more than $50 \%$ of the top coat delaminated from the substrate. In contrast, the TBCs with mesh structure only exhibited a $<10 \%$ spallation. This confirms that introduction of the mesh structure is an effective approach to improve the lifetime of the TBCs. In addition, the spallation degree decreased with an increase in the mesh spacing. Meanwhile, the spallation degree of samples with mesh varies over a relatively narrow range compared with reference TBCs. This could be attributed to the difference in failure mechanism.
Detailed examination of the reference TBCs revealed that horizontal cracks developed near the YSZ/TGO interface, causing the TBC fail through the edge delamination [Fig. 3(a) and (b)], which resulted in large-scale detachment of the top coat. While for the TBCs with mesh structure, small area spallation of the TBCs mainly occurred at the crest of the mesh, i.e., the cross-point between two mesh lines [Fig. 3(c)]. Several reasons might be responsible for this phenomenon: (1) the curved surface of the mesh causes the thermal misfit stress, either in the YSZ top coat or the TGO, to redistribute at the crest. ${ }^{11}$ Normal tension develops at the $\mathrm{TGO} /$ bond coat interface, as well as in the YSZ top coat, which nucleates and grows cracks in this vicinity ${ }^{12}$; (2) Upon cooling, the difference in the thermal expansion coefficient between mesh and YSZ could induce a large thermal misfit stress at the ceramic-metal interface, which leads to debonding of the top coat ${ }^{13}$; (3) During oxidation, fast-growing non-alumina scales like spinel tend to form at crest of mesh, which deteriorate the interfacial adhesion. ${ }^{14,15}$ At the same time, no apparent spallation between the mesh was observed. The Fig. 3(d) illustrated that the interfacial crack propagation between this area was impeded successfully by the mesh structure. Therefore, by reducing the crest density, i.e., increasing the mesh spacing, the spallation degree can be decreased, as shown in Fig. 2(c).

However, it should be noted that if the mesh spacing is too large, the cracks between mesh can easily coalesce and form large area delamination. There should exist an optimal spacing, which can reduce the spallation at the crest to the minimum. At the same time the coalescence of the cracks near the interface of top coat and bond coat could be
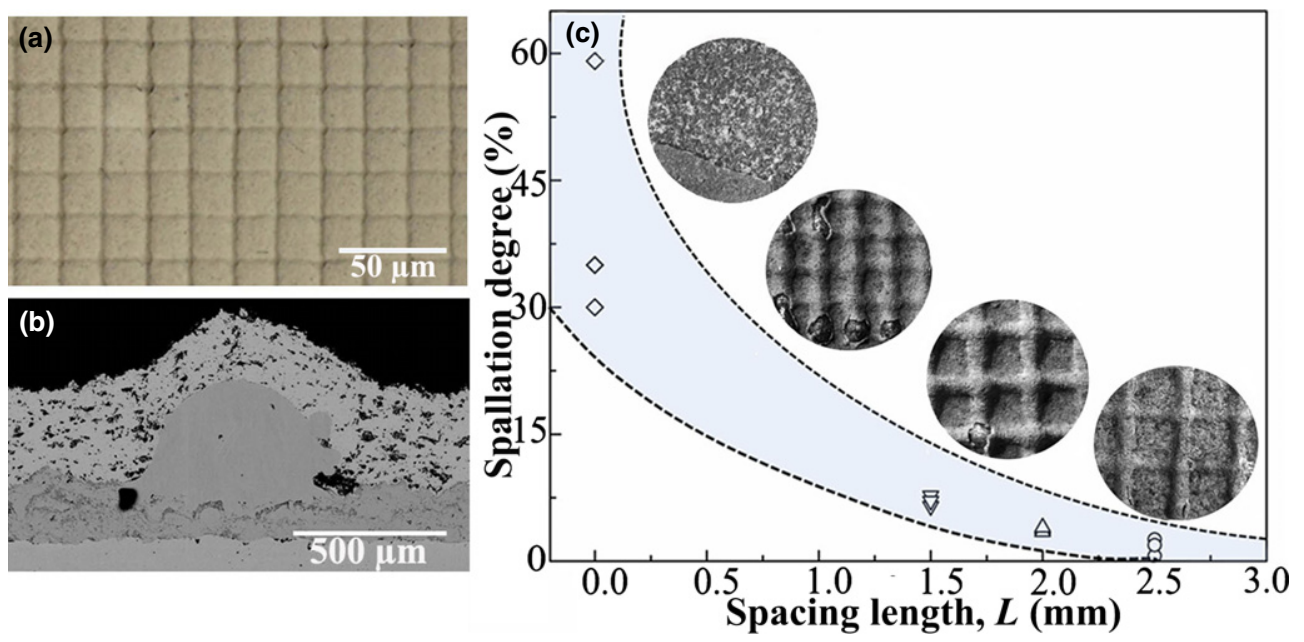

Fig. 2. (a) Optical photograph and (b) SEM micrograph of as-deposited samples with the mesh structure; (c) spallation degree of APS TBCs as a function of spacing length after 54 thermal cycles. The inset presents the surface topography of corresponding samples. 

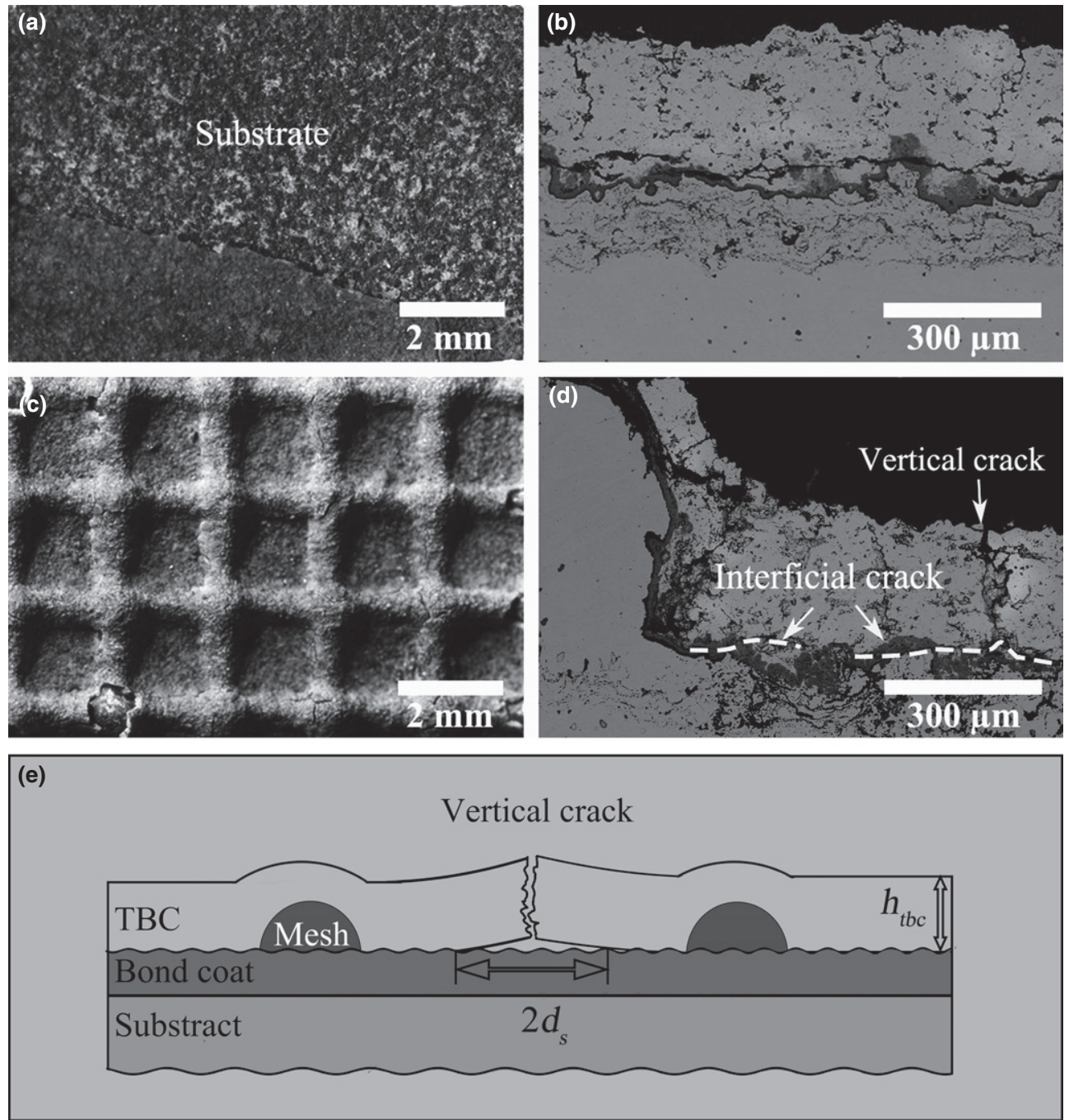

Fig. 3. (a) The spalled area and (b) cross-sectional image of standard APS TBCs; (c) the top surface and (d) the cross-section of the APS with mesh structure after 54 thermal cycles. The mesh spacing of this specimen is $2.0 \mathrm{~mm}$; (e) the schematic of the mode of a steady-state vertical crack with interfacial crack.

suppressed. As shown in Fig. 3(d), vertical crack presented in the YSZ top coat after thermal treatment, indicating a tensile stress. Such stress usually induces interfacial crack originating from the end of vertical cracks [Fig. 3(d)]. ${ }^{16}$ Considering interfacial delamination develops from the side of vertical cracks. The steady-state energy release rate for interfacial delamination form each side of vertical crack is as follows ${ }^{17}$ :

$$
G_{\mathrm{SS}}=Z^{*}\left(\frac{d}{h_{\mathrm{tbc}}}, \alpha, \beta\right) \frac{\sigma_{\mathrm{tbc}}^{2} h_{\mathrm{tbc}}}{\bar{E}_{\mathrm{tbc}}}
$$

where $Z^{*}$ is a dimensionless coefficient depending on the width of interfacial delamination $\left(\frac{d}{h_{\mathrm{tbc}}}\right) . \alpha$ and $\beta$ are Dundurs' parameters, given by ${ }^{18}$.

$$
\begin{aligned}
& \alpha=\frac{\bar{E}_{\mathrm{tbc}}-\bar{E}_{\mathrm{sub}}}{\bar{E}_{\mathrm{tbc}}+\bar{E}_{\mathrm{sub}}} \\
& \beta=\frac{1}{2} \frac{\left(1-2 v_{\mathrm{sub}}\right) / \mu_{\mathrm{sub}}-\left(1-2 v_{\mathrm{tbc}}\right) / \mu_{\mathrm{tbc}}}{\left(1-2 v_{\mathrm{sub}}\right) / \mu_{\mathrm{sub}}+\left(1-2 v_{\mathrm{tbc}}\right) / \mu_{\mathrm{tbc}}}
\end{aligned}
$$

where $\bar{E}=E / 1-v^{2}$ is the plain modulus, $E$ and $v$ are the Young's modulus and Poisson's ratio, and $\mu=E / 2(1+v)$ denotes the shear modulus. With $E_{\mathrm{tbc}}=50 \mathrm{GPa}$,
$E_{\text {sub }}=200 \mathrm{GPa}, v_{\mathrm{tbc}}=0.2$, and $v_{\mathrm{sub}}=0.3$, the Dundur's parameters are $\alpha=-0.61$ and $\beta=-0.24 .{ }^{19} d, h_{\mathrm{tbc}}$, and $\sigma_{\mathrm{tbc}}$ are interfacial crack width, thickness, and tensile stress of the top coat. The steady-state growth of vertical crack combination with interfacial delamination should satisfy an energetic condition:

$$
G_{\mathrm{SS}}^{*} \geq \Gamma_{\mathrm{f}}+W_{\mathrm{d}}
$$

The typical value for the fracture toughness $\Gamma_{\mathrm{f}}$ of APS TBC is approximately $30 \mathrm{~J} / \mathrm{m}^{2} .{ }^{19} W_{\mathrm{d}}$ is the energy required for interfacial delamination accompanying per unit area growth of vertical crack [see crack pattern in Fig. 3(e)], represented by:

$$
W_{\mathrm{d}} \approx 2 \Gamma\left(\Psi_{\mathrm{ss}}\right) \frac{d_{\mathrm{s}}}{h_{\mathrm{tbc}}}
$$

where $\Gamma\left(\Psi_{\mathrm{ss}}\right)$ is the mixed mode toughness depending on the phase angle $\Psi_{\mathrm{ss}}{ }^{20}$ :

$$
\Gamma\left(\Psi_{\mathrm{ss}}\right)=\Gamma_{\mathrm{tbc}}\left[1+\tan ^{2}\left((1-\lambda) \Psi_{\mathrm{ss}}\right)\right]
$$

where $\Gamma_{t b c}$ is the mode I toughness of interface of TBC and substrate. The phase angle is determined by stress intensity 
factors by $\Psi=\tan ^{-1}\left(K_{\mathrm{II}} / K_{\mathrm{I}}\right) . \lambda$ depends on the elastic mismatch. Substituting in appropriate values $(\alpha=-0.61$, $\left.\beta=-0.24, \quad \Gamma_{\mathrm{tbc}}=35 \mathrm{~J} / \mathrm{m}^{2}\right)$, we have $\Psi_{\mathrm{ss}}=55^{\circ}, \lambda=0.41$, $\Gamma\left(\Psi_{\mathrm{ss}}\right)=46 \mathrm{~J} / \mathrm{m}^{2}{ }^{16,21}$ In this study, the thickness of top coat $h_{\mathrm{tbc}}$ is $200 \mu \mathrm{m}$ and the tensile stress in the YSZ top coat is about $150 \mathrm{MPa}$, measured using Raman spectroscopy. ${ }^{22,23}$ The predicted stable interfacial crack length $d_{s}$ is approximately $3 \mathrm{~mm}$ according to Eqs. (1), (3), and (4). Assuming that the vertical crack located in the middle of two meshes, the optimal spacing is around $6 \mathrm{~mm}$. That is to say, if the mesh spacing is larger than this value, the mesh loses its role on impeding the propagation of interfacial cracks. However, it should be noted that the above calculation is a rough estimation. The accurate value relies on the determination of interfacial toughness and phase angle, etc.

Figure 3 clearly demonstrated that the propagation of interfacial crack can be impeded by the mesh structure. However, the high mesh could lead to large surface roughness or even nonflat surface of the top coat, which in turn, affects the aerodynamics or heat transfer of the coated blade in engine application. For instance, the large mesh could introduce local hotspots at the crest of the mesh. This could lead to premature failure of the TBCs at such positions. Therefore, it is worthwhile to determine the optimal height of the mesh.

In TBC system, the residual stress is influenced by the curvature of the interface. For concave interface, radial tensile stress developed at the interface, which plays an important role in nucleation and propagation of radial crack close to the interface. Therefore, understanding the radial stress around the crest of curved surface is crucial for lifetime prediction. ${ }^{24} \mathrm{~A}$ two-concentric-cylinder model was employed to estimate the stress state around the crest of the mesh. The radius $R$ of mesh with height of $h$ and width of $w$ (see the inset in Fig. 4) is represented by:

$$
\begin{array}{cc}
R=\frac{4 h^{2}-w^{2}}{8 h} & (\text { for } h<w / 2) \\
R=250 & (\text { for } h \geq w / 2)
\end{array}
$$

where $h$ and $w$ are the height and width of mesh, respectively. It is assumed that the residual stress caused only by the thermal misfit of the coating and substrate when the TBCs cool from $1150^{\circ} \mathrm{C}$ to ambient temperature $\left(20^{\circ} \mathrm{C}\right)$. For a rough estimation, the TBCs are treated as stress free at oxidation temperature. The dependence of radial stress on height (i.e., radius) of the mesh is calculated by ${ }^{25}$ :

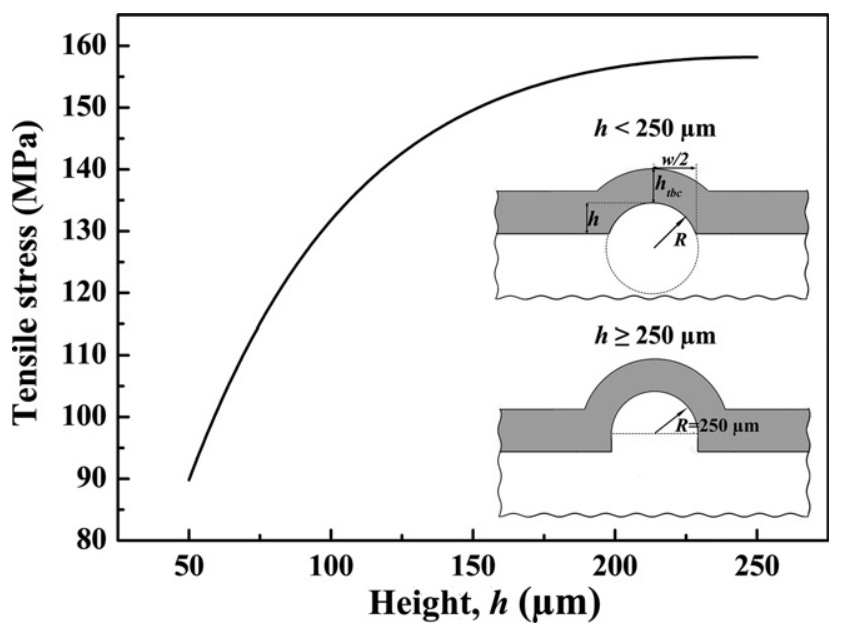

Fig. 4. Radial stress at the interface of coating/substrate for different mesh height. The inset shows the schematic of two concentric cylinder model in TBCs with mesh height below and exceeding $250 \mu \mathrm{m}$.

$$
\sigma_{r}(r=R)=-\frac{E_{\mathrm{tbc}}\left(\alpha_{\mathrm{sub}}-\alpha_{\mathrm{tbc}}\right) \Delta T\left[\left(\frac{R+h_{\mathrm{tbc}}}{R}\right)^{2}-1\right]}{1-2 v_{\mathrm{tbc}}+\left(\frac{R+h_{\mathrm{tbc}}}{R}\right)^{2}+\frac{E_{\mathrm{tbc}}}{E_{\mathrm{sub}}}\left(\frac{1-v_{\mathrm{sub}}}{1+v_{\mathrm{tbc}}}\right)\left[\left(\frac{R+h_{\mathrm{tbc}}}{R}\right)^{2}-1\right]}
$$

The thermal expansion coefficient of top coat $\alpha_{\text {tbc }}$ and substrate $\alpha_{\text {sub }}$ is $11 \times 10^{-6} / \mathrm{K}$ and $16 \times 10^{-6} / \mathrm{K}$, respectively. The width of mesh $w$ is $500 \mu \mathrm{m}$, limited by diameter of nozzle. When the height of mesh is less than the half of width $(250 \mu \mathrm{m})$, the tensile stress at the crest of the mesh increases with an increase in the radius, as shown in Fig. 4 . When the height exceeding $250 \mu \mathrm{m}$, the radius $R$ keeps constant about $250 \mu \mathrm{m}$. Based on Eq. (7), the stress caused by thermal misfit will not increase with further increasing the height. This indicated that lowering the height of mesh is benefit for enhancing the lifetime of TBCs when height is less than $250 \mu \mathrm{m}$. However, while the height $h$ is lower than the critical value, the interface cracks will coalesce with horizontal crack, forming large-scale delamination. Meanwhile, the spallation of the top coat will be accelerated because of the tensile stress caused by mesh, compared with traditional TBCs.

To verify the effect of mesh height on TBCs, meshes with height of 330 and $130 \mu \mathrm{m}$ were applied between the bond coat and the substrate. The samples were thermal treated at $1150^{\circ} \mathrm{C}$ for 54 cycles. The spallation degree was shown in Fig. 5 and the results of samples with mesh height of $500 \mu \mathrm{m}$ (mesh located between the bond coat and the top coat) were included for comparison. The spallation degree decreased as the height decreased, demonstrating that lower height of mesh is beneficial for lifetime. The inset shows that the crack shows the surface of sample with mesh height of $330 \mu \mathrm{m}$, illustrating the deflection of crack due to the existence of mesh. Figure 6 presents the cross-sectional image of the APS TBCs with different mesh height. For TBCs with mesh height of $500 \mu \mathrm{m}$, debonding of the top coat from the crest of mesh was severe. In contrast, for TBCs with mesh height of $130 \mu \mathrm{m}$, the horizontal crack propagated along the YSZ/ TGO interface and coalesced. This implies that once the mesh height is below a lower limit, for example, $130 \mu \mathrm{m}$ in this study, the crack impeding effect will disappear and the failure behavior is identical with the standard APS TBCs. However, if the height exceeding the upper limit (e.g., $330 \mu \mathrm{m}$, Fig. 5), severe cracking around the mesh develops, which could be attributed to the vertical crack formed during the process of deposition. Under thermal cycling, tensile stress arises at the surface of top coat and substrate. Therefore, interface delamination will generate from the root of the vertical crack, leading to spallation. As shown in

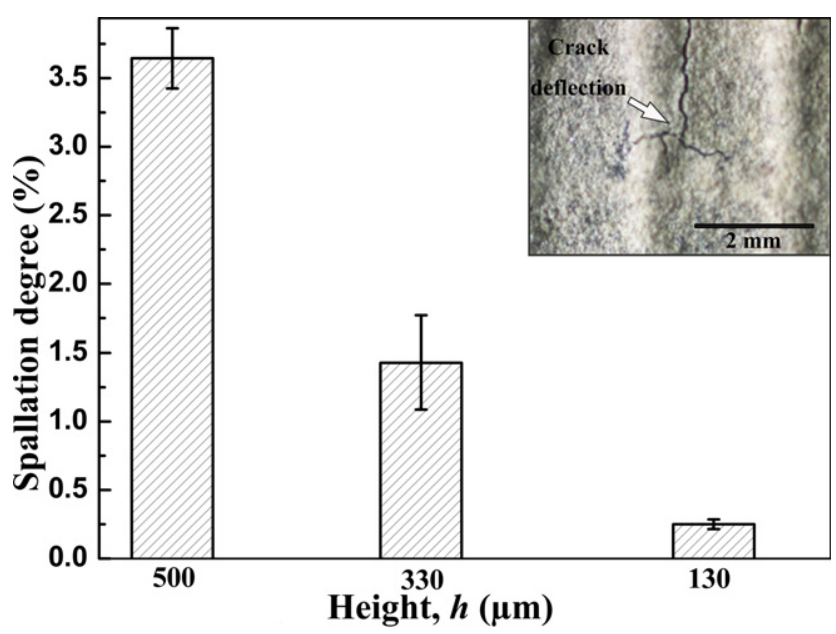

Fig. 5. Spallation degree of APS TBCs with different mesh height after 54 thermal cycles. The inset shows the impeding effect of mesh on cracks propagation. 

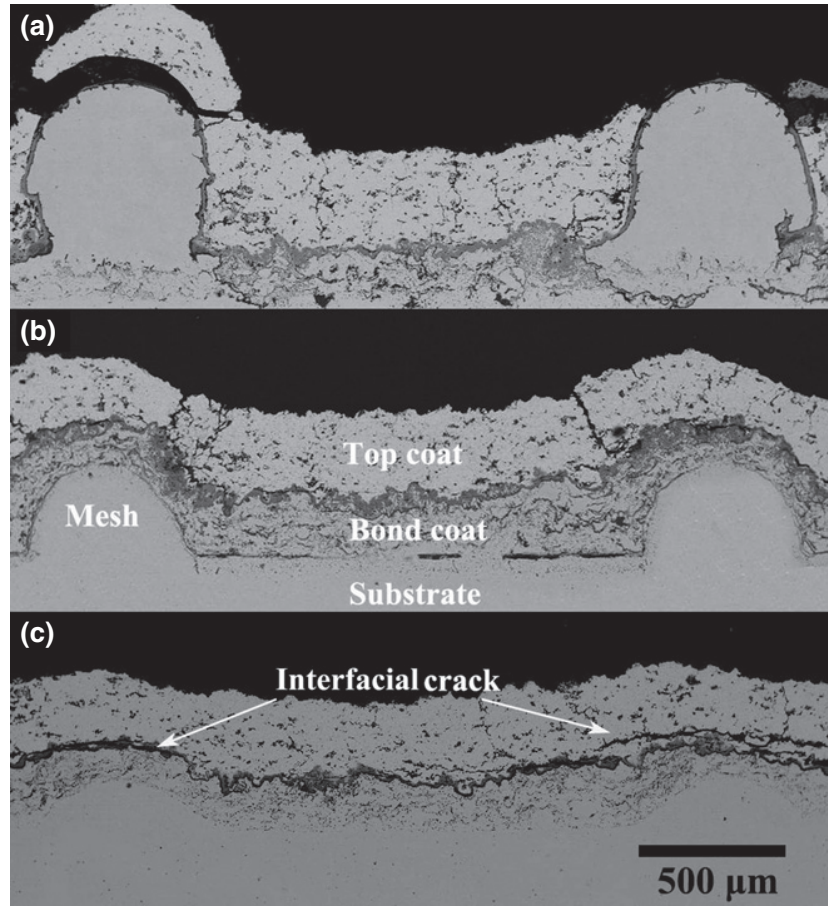

Fig. 6. SEM images of samples after 54 cycles at $1150^{\circ} \mathrm{C}$ with mesh height of: (a) 500; (b) 330; and (c) $130 \mu \mathrm{m}$.

Fig. 6(a), the thickness of top coat around the mesh, especially for TBCs with mesh up to $500 \mu \mathrm{m}$, is thinner than the coating at other region. When the height of mesh decreasing, the coatings thickness achieves better uniformity and the surface roughness of TBC decreases as shown in Fig. 6(c). Based on preliminary results, the optimal height should be in the range $130-330 \mu \mathrm{m}$ for the samples investigated in this study. In addition, compared with mesh applied on the surface of the substrate [Figs. 6(b) and (c)], the mesh applied on the bond coat surface [Fig. 6(a)] have a smoother interface which deteriorates the interfacial adhesion and causes debonding. The mesh deposited directly on the substrate surface is more beneficial to the TBCs durability.

\section{Conclusions}

In summary, the LPD technique was employed to create three-dimensional mesh structure at the coating-substrate interface of APS TBCs. With the mesh structure, the spallation degree decreased from more than $50 \%$ for reference APS TBCs to less than $10 \%$ after the same thermal treatment. It was suggested that mesh is effective in impeding the propagation of crack along the interface, significantly improving the lifetime of TBCs. There should exist an optimal value for the mesh height and spacing, at which the TBCs exhibit the longest durability. This work demonstrated that manipulating the interfacial microstructure is a potential approach to improve the lifetime of the TBC, particularly in making thick TBCs. More systematic work is being carried out to optimize the mesh structure and geometry parameters.

\section{Acknowledgments}

The authors wish to thank the financial support from the "1000 Plan" Program, the Program for Professor of Special Appointment (Eastern Scholar) at
Shanghai Institutions of Higher Learning (no. SHDP201303), and the National Natural Science Foundation of China (no. 51271120).

\section{References}

${ }^{1}$ D. R. Clarke and S. R. Phillpot, "Thermal Barrier Coating Materials," Mater. Today, 82 [6] 22-9 (2005).

${ }^{2}$ N. Markocsan, P. Nylen, J. Wigren, and X. H. Li, "Low Thermal Conductivity Coatings for Gas Turbine Application," J. Therm. Spray. Techn, 16 [4] 498-505 (2007).

${ }^{3}$ X. Chen, J. W. Hutchinson, M. Y. He, and A. G. Evans, "On the Propagation and Coalescence of Delamination Cracks in Compressed Coatings: With Application to Thermal Barrier Systems," Acta Mater., 51, 2017-30 (2003).

${ }^{4}$ D. R. Clarke and C. G. Levi, "Material Design for Next Generation Thermal Barrier Coating," Annu. Rev. Mater. Res., 33, 383-417 (2003).

${ }^{5}$ A. G. Evans, D. R. Mumm, J. W. Hutchinson, G. H. Meier, and F. S. Pettit, "Mechanisms Controlling the Durability of Thermal Barrier Coatings," Prog. Meter. Sci, 46, 505-53 (2001).

${ }^{6} \mathrm{~B}$. Zhou and K. Kokini, "Effect of Surface Pre-Crack Morphology on the Fracture of the Thermal Barrier Coatings Under Thermal Shock," Acta Mater., 52 [14] 4189-97 (2004).

${ }^{7}$ N. P. Padture, M. Gell, and E. H. Jordan, "Thermal Barrier Coatings for Gas-Turbine Application," Science, 296 [5566] 280-4 (2002).

${ }^{8}$ K. M. Carling and E. A. Cater, "Effects of Segregating Elements on the Adhensive Strength and Structure of the $\alpha-\mathrm{Al}_{2} \mathrm{O}_{3} / \beta-\mathrm{NiAl}$ Interface," Acta Mater., 55, 2791-803 (2007).

${ }^{9}$ P. Y. Hou, T. Izumi, and B. Gleeson, "Sulfur Segregation at $\mathrm{Al}_{2} \mathrm{O}_{3} / \gamma-$ $\mathrm{Ni}+\gamma$ ' $-\mathrm{Ni}_{3} \mathrm{Al}$ Interfaces: Effects of $\mathrm{Pt}, \mathrm{Cr}$ and $\mathrm{Hf}$ Additions," Oxid. Met., 72, 109-24 (2009).

${ }^{10} \mathrm{~S}$. Amada and T. Hirose, "Influence of Grit Blasting Pre-Treatment on the Adhesion Strength of Plasma Sprayed Coatings: Fracture Analysis of Roughness," Surf. Coat. Tech, 102 [1] 132-7 (1998).

${ }^{11}$ M. Y. He, A. G. Evans, and J. W. Hutchinson, "Effects of Morphology on the Decohesion of Compressed Thin Films," Mater. Sci. Eng., A, 245 [2] 168-81 (1998).

${ }^{12}$ P. K. Wright and A. G. Evans, "Mechanisms Governing the Performance of Thermal Barrier Coatings," Curr. Opin. Solid State Mater. Sci., 4 [3] 25565 (1999).

${ }^{13} \mathrm{~V}$. K. Tolpygo and D. R. Clarke, "Wrinkling of $\alpha$-Alumina Films Grown by Oxidation-II. Oxide Separation and Failure," Acta Mater., 46 [14] 5167-74 (1998).

${ }^{14}$ E. P. Busso, H. E. Evans, Z. Q. Qian, and M. P. Taylor, "Effects of Breakaway Oxidation on Local Stresses in Thermal Barrier Coatings," Acta Mater., 58 [4] 1242-51 (2010).

${ }^{15}$ C. H. Hsueh, J. A. Haynes, M. J. Lance, P. F. Becher, M. K Ferber, et al., "Effects of Interface Roughness on Residual Stresses in Thermal Barrier Coatings," J. Am. Ceram. Soc., 82 [4] 1073-5 (1999).

${ }^{16}$ S. Kramer, S. Faulhaber, M. Chambers, D. R. Clarke, C. G. Levi, et al., "Mechanisms of Cracking and Delamination Within Thick Thermal Barrier Systems in Aero-Engines Subject to Calcium-Magnesium-Alumino-Silicate (CMAS) Penetration," Mater. Sci. Eng., A, 490 [1] 26-35 (2008).

${ }^{17}$ H. X. Mei, Y. Y. Pang, and R. Huang, "Influence of Interfacial Delamination on Channel Cracking of Elastic Thin Films," Int. J. Fract., 148, 331-42 (2007).

${ }^{18}$ Z. C. Xia and J. W. Hutchinson, "Crack Patterns in Thin Film," J. Mech. Phys. Solids, 48 1107-31 (2000).

${ }^{19}$ A. M. Limarga, R. Vaßen, and D. R. Clarke, "Stress Distributions in Plasma-Sprayed Thermal Barrier Coatings Under Thermal Cycling in a Temperature Gradient,” J. Appl. Mech., 78 [1] 011003, 8pp (2011).

${ }^{20}$ A. G. Evans and J. W. Hutchinson, "The Mechanics of Coating Delamination in Thermal Gradients," Surf. Coat. Tech, 201 [18] 7905-16 (2007).

${ }^{21}$ R. G. Hutchinson and J. W. Hutchinson, "Lifetime Assessment for Thermal Barrier Coatings: Tests for Measuring Mixed Mode Delamination Toughness," J. Am. Ceram. Soc., 94 [S1] S85-95 (2011).

${ }^{22}$ A. M. Limarga and D. R. Clarke, "Piezo-Spectroscopic Coefficients of Tetragonal-Prime Yttria-Stabilized Zirconia," J. Am. Ceram. Soc., 90 [4] 1272-5 (2007).

${ }^{23}$ M. Tanaka, M. Hasegawa, A. F. Dericioglu, and Y. Kagawa, "Measurement of Residual Stress in Air Plasma-Sprayed $\mathrm{Y}_{2} \mathrm{O}_{3}-\mathrm{ZrO}_{2}$ Thermal Barrier Coating System Using Micro-Raman Spectroscopy," Mater. Sci. Eng., A, 419, 262-8 (2006).

${ }^{24}$ M. Ahrens, R. Vaßen, and D. Stover, "Stress Distributions in PlasmaSprayed Thermal Barrier Coatings as a Function of Interface Roughness and Oxide Scale Thickness," Surf. Coat. Tech, 161, 26-35 (2002).

${ }^{25}$ X. Y. Gong and D. R. Clarke, "On the Measurement of Strain in Coatings Formed on a Wrinkled Elastic Substrate," Oxid. Met., 50 [516] 355-75 (1998). 